\title{
Cross sectional observation of the effects of carbon disulphide on the nervous system, endocrine system, and subjective symptoms in rayon manufacturing workers
}

Toru Takebayashi, Kazuyuki Omae, Chizuru Ishizuka, Tetsuo Nomiyama, Haruhiko Sakurai

\begin{abstract}
Objectives-A prospective cohort study was initiated to clarify whether the current level of exposure to carbon disulphide $\left(\mathrm{CS}_{2}\right)$ is low enough to prevent occurrence of subclinical health impairments or to ameliorate health effects due to past high exposure. This paper describes the effects of exposure to $\mathrm{CS}_{2}$ on the nervous and endocrine systems, and the subjective symptoms in a baseline observation.

Methods-The effects were evaluated of $\mathrm{CS}_{2}$ on the median nerve conduction velocity, neurobehavioural and psychological tests, and subjective symptoms related to solvents in 432 male workers exposed to $\mathrm{CS}_{2}$ and 402 reference workers from 11 rayon factories in Japan. Adjustment was made for potential confounding factors such as age or alcohol drinking. Exposure to $\mathrm{CS}_{2}$ was either dichotomised or categorised into three groups by job type.
\end{abstract}

Results-Reductions were observed in motor $(-1.9 \mathrm{~m} / \mathrm{s})$ and sensory $(-0.91 \mathrm{~m} / \mathrm{s}$ for orthodromic and $\mathbf{- 1 . 1} \mathrm{m} / \mathrm{s}$ for antidromic) nerve conduction velocities in the workers exposed to $\mathrm{CS}_{2}$ at the spinning and refining processes. Small but significant increases were found in self rated depression scale score and decrease in digit span (backward) in the workers exposed to $\mathrm{CS}_{2}$. Of 54 subjective symptoms many were increased-namely, heavy feeling in the head, light headedness, fainting after suddenly standing up, tremor, dullnes, and increased sensitivity of skin in the extremities, reduced grasping power, reduced sexual desire, and increased rough skin. The endocrinological indicator-the concentration of glycosylated haemoglobin-was also increased in the workers exposed to $\mathbf{C S}_{2}$.

Conclusions-Subclinical effects on the nervous system and on glucose metabolism were found in the workers exposed to $\mathrm{CS}_{2}$. One interpretation is that relatively higher exposure to $\mathrm{CS}_{2}$ in the past may induce these, but the effects are still not entirely ameliorated under the current exposure to $\mathrm{CS}_{2}$. Another possibility is that the current exposure to $\mathrm{CS}_{2}$ may cause these positive findings. A follow up observation is necessary to clarify these questions.

(Occup Environ Med 1998;55:473-479)
Keywords: carbon disulphide; nervous system; endocrine system

Much evidence has documented the adverse effects of exposure to carbon disulphide $\left(\mathrm{CS}_{2}\right)$ on many organs. The nervous system and the cardiovascular system are the principal targets affected by exposure to $\mathrm{CS}_{2} .{ }^{1}$ In the nervous system, acute poisoning - such as psychosishas occurred after severe exposure $(>500$ $1000 \mathrm{ppm}$ ) in the past, and more recently chronic effects on the peripheral and central nervous systems were noted with low level, long term exposure. One of the clinical manifestations of $\mathrm{CS}_{2}$ intoxication in the peripheral nerves is polyneuropathy with paraesthesia, dysaesthesia, fatigue, and diffuse pains in the lower limbs. ${ }^{2}$ Subclinical effectssuch as reduction in the peripheral nerve conduction velocity, neurobehavioural and psychological changes - and increased subjective complaints have been detected with sensitive neurological and psychological techniques at various concentrations of $\mathrm{CS}_{2}$ including low concentrations of $\mathrm{CS}_{2}$ of $10-20 \mathrm{ppm}$ or even $<10$ ppm..$^{3-8}$ Effects of $\mathrm{CS}_{2}$ on liver functions ${ }^{2}$ or the endocrine system have also been pointed out, including glucose metabolism ${ }^{10}$ and functions of the adrenal, thyroid, gonad, and the hypothalamo-hypophysial axis. ${ }^{11-17}$ However, few epidemiological studies were prospectively designed to examine the effects of low level exposure to $\mathrm{CS}_{2}$ on the nervous and endocrine systems.

A remaining question to be answered is whether current exposure to $\mathrm{CS}_{2}$ is low enough to prevent occurrence of health impairments related to $\mathrm{CS}_{2}$ or to ameliorate health effects due to past high exposure. We thus initiated a prospective cohort study in all Japanese rayon factories with sensitive indicators of subclinical changes. In this paper, the effects of $\mathrm{CS}_{2}$ on the nervous system and the endocrine system, as well as the subjective symptoms found in a baseline study of 1992 will be presented.

\section{Subjects and methods}

STUDY DESIGN AND STUDY POPULATION

The study subjects were 432 male workers exposed to $\mathrm{CS}_{2}$ and 402 reference workers in 11 viscose rayon manufacturing factories in Japan, as stated in the accompanying paper. ${ }^{18}$ Subjective symptoms related to solvents, 
psychological tests, smoking habits, and alcohol consumption were surveyed through a self administered questionnaire. Measurement of the peripheral nerve conduction velocity and a neurobehavioural test were done by our research team at factory sites without knowledge of the examinees' exposure status. Information on age, educational history, height, weight, and history of job categories was obtained from company records.

When the workers exposed to $\mathrm{CS}_{2}$ were divided into two groups by their job type (from the research team visit in 1992), there were 309 workers at spinning or refining processes and 123 workers at other exposed jobs. The spinning and refining workers were assigned to the same group because exposure concentration to $\mathrm{CS}_{2}$ at these two processes is known to be higher than the exposure at other processes. The geometric mean (geometric SD) of urinary 2-thiothiazolidine-4-carboxylic acid (TTCA), measured twice in 1992, was 3.13 (2.27) $\mathrm{mg} / \mathrm{g} \mathrm{Cr}$ for the spinning or refining workers and $1.28(2.01) \mathrm{mg} / \mathrm{g}$ creatinine $(\mathrm{Cr})$ for the other exposed workers. One hundred and four $(34.6 \%)$ out of 301 spinning or refining workers had $>5 \mathrm{mg} / \mathrm{g} \mathrm{Cr}$ of TTCA, but only two $(1.7 \%)$ out of 121 other exposed workers were above this concentration. Mean (SD) age and duration of exposure to $\mathrm{CS}_{2}$ were 34.9 (8.0) and $13.8(8.2)$ years for the spinning or refining workers, and 36.9 (8.3) and 12.6 (8.1) years for the other exposed workers. Some of the study subjects experienced job transfer; $17(5.5 \%)$ of the spinning or refining workers had work experience at the other exposed processes, and 19 (15.4\%) of the other exposed workers were engaged in the spinning or refining processes.

For the reference workers, chance of exposure to $\mathrm{CS}_{2}$ should be trivial because they were chosen from either non-rayon factories or jobs not exposed to $\mathrm{CS}_{2}$. This was further confirmed by urinary TTCA measurement in 1992 , in which all of the specimens were below the lower detectable limit $(0.5 \mathrm{mg} / \mathrm{l})$. Eight reference workers $(2.0 \%)$ had worked at exposed processes for $\geqslant 5$ years in the past. No one, however, had been transferred due to deterioration in health.

Distributions of potential risk factors such as body mass index (BMI) or drinking habit were comparable across the three groups (data not shown), except for the percentage of current smokers and graduates of senior high school or higher $(72.5 \%$ and $61.5 \%$ for the spinning or refining workers, $72.1 \%$ and $70.7 \%$ for the other exposed workers, and $62.7 \%$ and $70.9 \%$ for the reference workers, respectively).

EFFECTS ON THE NERVOUS SYSTEM

Peripheral nerve conduction velocity

Motor and sensory nerve conduction velocities of the median nerve were measured (Neuropack, Nihon Kohden, Tokyo). Motor conduction velocity was assessed at the elbowwrist segment, and both orthodromic and antidromic sensory conduction velocity were assessed at the finger (digit II)-wrist segment. A surface electrode was used, and supramaxi- mal stimulation was given. Surface skin temperature was maintained above $30^{\circ} \mathrm{C}$ throughout the measurement to prevent a low temperature effect on the velocity.

\section{Neurobehavioural tests}

The test battery was designed to be completed in 20 minutes because of time limitation, and consisted of finger tapping (both dominant and non-dominant hands), simple reaction time, choice reaction time, digit span (memorising forward and backward), and the Benton visual retention test. The computer program used was written by $\mathrm{KO}$, and each item was shown on the computer screen. Before the measurement, each examinee was given the opportunity to familiarise himself with the test procedures. The median value of the tapping intervals or the reaction times was used as the summary measure of the test result for each examinee. For digit span, the maximal digit number of the correct answer was recorded. One trained person scored the Benton visual retention test without any knowledge of exposure status, and average number of errors were reported.

Subjective symptoms and psychological tests Prevalence was examined by the questionnaire of 54 subjective symptoms that could be experienced as a result of exposure to organic solvents (appendix, derived from Inoue ${ }^{19}{ }^{20}$ ). The questions covered various effects of solvents, including effects on the central nervous system, the peripheral nerves, the gastrointestinal system, and the skin. The subject was asked about the frequency of a given symptom within the past six months: "Choose from the following three grades: always, occasionally, not experienced". The questionnaire also included psychological tests, by which the mood of the study subject was evaluated. The test scales used were the manifest anxiety scale $^{21}$ and the self rated depression scale. ${ }^{22}$ Reliability of the answers in the questionnaire was checked by evaluating the lie scale score in the manifest anxiety scale, which is thought to reflect the subject's honest attitude. No questionnaire was excluded from the analysis if a cut off point of the lie scale score was set at $\geqslant 11$.

EFFECTS ON THE ENDOCRINE SYSTEM AND OTHER BIOCHEMICAL VARIABLES

Various blood indices of the endocrine system were measured. Those were blood glucose, glycosylated haemoglobin, and serum insulin concentration for glucose metabolism, serum or plasma follicle stimulating hormone (FSH), luteinising hormone (LH), and adrenocorticotrophic hormone (ACTH) for the hypothalamo-hypophysial axis, testosterone for gonadal function, and thyroid stimulating hormone (TSH), triiodothyronine (T3), thyroxine (T4), and thyroxine binding globulin (TBG) for thyroid function. Some serum biochemical markers were also measured, including aspartate aminotransaminase (AST), alanine aminotransaminase (ALT), $\gamma$-glutamyl transpeptidase $(\gamma-\mathrm{GTP})$, total protein (TP), alkaline 
Table 1 Effects of exposure to $\mathrm{CS}_{2}$ on psychological and neurobehavioral tests, and median nerve conduction velocity

\begin{tabular}{lll}
\hline Test items & Exposed to $C S_{2}$ & Reference \\
\hline Median nerve conduction velocity: & $\mathrm{n}=419$ & $\mathrm{n}=390$ \\
Motor nerve (m/s) & $57.42(3.89)^{\star \star}$ & $58.98(3.48)$ \\
Sensory nerve (orthodromic) (m/s) & $53.18(4.76)^{\star}$ & $53.92(4.47)$ \\
Sensory nerve (antidromic) (m/s) & $52.07(4.73)^{\star \star}$ & $52.95(4.26)$ \\
Psychological test: & & \\
Manifest anxiety scale & $\mathrm{n}=377$ & $\mathrm{n}=347$ \\
& $18.2(7.8)$ & $18.0(7.6)$ \\
Self rated depression scale & $\mathrm{n}=413$ & $\mathrm{n}=371$ \\
& $38.3(8.2)^{\star \star}$ & $36.7(7.8)$ \\
& & \\
Neurobehavioural test: & $\mathrm{n}=420$ & $\mathrm{n}=391$ \\
Tapping (dominant hand) (ms) $\dagger$ & $135.8(1.1)$ & $134.9(1.1)$ \\
Tapping (non-dominant hand) (ms) $\dagger$ & $150.2(1.2)$ & $150.2(1.2)$ \\
Simple reaction time (ms) $\dagger$ & $256.5(1.2)$ & $258.6(1.2)$ \\
Choice reaction time (ms) $\dagger$ & $672.4(1.3)$ & $667.7(1.4)$ \\
Digit span (forward) & $5.9(1.5)$ & $6.0(1.5)$ \\
Digit span (backward) & $4.5(1.5)^{\star}$ & $4.7(1.5)$ \\
Benton visual retention test (mean errors (n)) $\neq$ & $1.0(0.6-1.4)$ & $1.0(0.6-1.6)$ \\
\hline
\end{tabular}

${ }^{\star} \mathrm{p}<0.05 ;{ }^{\star \star} \mathrm{p}<0.01$.

†Geometric mean (GSD).

$\ddagger$ Median (interquartile range).

Values are mean (SD) unless otherwise specified.

phosphatase (ALP), lactate dehydrogenase (LDH), total bilirubin, and uric acid. A blood sample was collected from each participant without fasting, and was sent to a nationwide clinical laboratory within a day. Standard analytical methods were used-that is, radioimmunoassays for hormones, UV methods for AST and ALT, an enzymatic method for glucose, high performance liquid chromatography (HPLC) for glycosylated haemoglobin, the L- $\gamma$-glutamyl-3-carboxy-4-nitroanilide substrate method for $\gamma$-GTP, the Biuret method for TP, the 4-nitorphenylphosphate substrate method for ALP, the Wroblewski-LaDue method for LDH, the diazotisation (Jendrassik-Grof) method for total bilirubin, and the uricase method for uric acid. ${ }^{23}{ }^{24}$ The laboratory ran internal and external quality control programmes to minimise measurement variation.

\section{STATISTICAL ANALYSIS}

Exposure status was first dichotomised (workers exposed to $\mathrm{CS}_{2}$ and reference workers), and then categorised into three groups (spinning or refining workers, other exposed workers, and reference workers) according to the current job type without any consideration for past job changes. Separate analysis which excluded workers who had changed jobs showed similar results. A subjective symptom was considered prevalent when a subject's response was either always or occasionally. Frequencies of symptoms were compared by $\chi^{2}$ test or Fisher's exact method without any adjustment for the multiplicity of comparisons. For continuous data, normality of data distribution was examined, and an appropriate transformation was done to obtain a normal distribution before the analysis. Mean values of the variables were calculated and compared by student's $t$ test or Welch's method (two means comparison), or by analysis of variance (ANOVA) followed by Tukey's method (group comparison). Nonparametric methods-that is, the Wilcoxon rank sum test and the Kruskal-Wallis testwere used when appropriate.

To control for possible confounders simultaneously, multiple linear regression models for the continuous outcome variables and multiple logistic regression models for the subjective symptoms were developed. Potential confounding factors included in the models were age $(<30,30-9, \geqslant 40$ years $)$, body mass index (BMI) $\left(\mathrm{kg} / \mathrm{m}^{2}\right)$, education level (junior high school, senior high school, or higher), smoking habit (never, past, current $(<29, \geqslant 30$ cigarettes/day)), and alcohol intake (never, occasional, habitual $(<45, \geqslant 45 \mathrm{~g}$ ethanol/day)). The effectiveness of all constructed models in describing outcome variables was checked by residual and collinearity analysis.

Some of the data were missing because of absence on the day of a research team visit or incompleteness of the questionnaire. This occurred, however, without any relation to exposure or health. All statistical analysis was done with the SAS package (Cary, NC).

\section{Results}

EFFECTS ON THE NERVOUS SYSTEM

Peripheral nerve conduction velocity

Both motor conduction velocity and sensory conduction velocities of the median nerve were lower in the workers exposed to $\mathrm{CS}_{2}$ (table 1), and these changes stayed significant in the multiple regression models. The effects were then examined relative to three job categories. Table 2 shows crude mean values among the three groups and adjusted differences from the reference group. Clearly, the motor and

Table 2 Median nerve conduction velocity $(\mathrm{m} / \mathrm{s})$ by exposure to $\mathrm{CS}_{2}$ job category

\begin{tabular}{|c|c|c|c|c|}
\hline Type of the nerve & Group & $\begin{array}{l}\text { Conduction } \\
\text { velocity } \\
\text { (mean (SD)) }\end{array}$ & Adjusted differencet ( $95 \%$ CI) & $p$ Valuet \\
\hline Motor nerve & $\begin{array}{l}\text { Reference } \\
\text { Exposed to } \mathrm{CS}_{2} \text { (other than spinning or refining) } \\
\text { Exposed to } \mathrm{CS}_{2} \text { (spinning or refining) }\end{array}$ & $\begin{array}{l}58.98(3.48) \\
58.33(3.43) \\
57.06(4.01)^{\star}\end{array}$ & $\begin{array}{l}-0.51(-1.26 \text { to } 0.26) \\
-1.94(-2.51 \text { to }-1.38)\end{array}$ & $\begin{array}{r}0.1868 \\
\mathrm{p}<0.0001\end{array}$ \\
\hline Sensory nerve (orthodromic) & $\begin{array}{l}\text { Reference } \\
\text { Exposed to } \mathrm{CS}_{2} \text { (other than spinning or refining) } \\
\text { Exposed to } \mathrm{CS}_{2} \text { (spinning or refining) }\end{array}$ & $\begin{array}{l}53.92(4.47) \\
53.58(4.55) \\
53.02(4.85)^{\star}\end{array}$ & $\begin{array}{l}-0.18(-1.11 \text { to } 0.76) \\
-0.91(-1.62 \text { to }-0.20)\end{array}$ & $\begin{array}{l}0.7121 \\
0.0124\end{array}$ \\
\hline Sensory nerve (antidromic) & $\begin{array}{l}\text { Reference } \\
\text { Exposed to } \mathrm{CS}_{2} \text { (other than spinning or refining) } \\
\text { Exposed to } \mathrm{CS}_{2} \text { (spinning or refining) }\end{array}$ & $\begin{array}{l}52.95(4.26) \\
52.59(4.34) \\
51.86(4.87)^{\star}\end{array}$ & $\begin{array}{l}-0.14(-1.04 \text { to } 0.76) \\
-1.15(-1.83 \text { to }-0.46)\end{array}$ & $\begin{array}{l}0.7616 \\
0.0010\end{array}$ \\
\hline
\end{tabular}

${ }^{\star} \mathrm{p}<0.05$.

†Adjusted for age, BMI, education, smoking, alcohol intake, and exposure to $\mathrm{CS}_{2}$. Regression coefficient $(95 \% \mathrm{CI})$ and $\mathrm{p}$ value for variables of exposure to $\mathrm{CS}_{2}$ in the multiple regression models are indicated.

Number of the spinning or refining, other exposed jobs, and reference workers analysed were 299, 120, and 390, respectively.

Mean nerve conduction velocities were compared among three job categories by ANOVA, and then Tukey's method. 
Table 3 Prevalence (\%) of the most frequent symptoms in the workers exposed to $\mathrm{CS}_{2}$

\begin{tabular}{lll}
\hline Symptom & $\begin{array}{l}\text { Exposed to } C S_{2} \\
n=417\end{array}$ & $\begin{array}{l}\text { Reference } \\
n=379\end{array}$ \\
\hline Q1 Heavy feeling in the head & $23.5^{\star \star}$ & 15.3 \\
Q10 Light headedness & $17.0^{\star}$ & 11.2 \\
Q18 Fainting after suddenly standing up & $34.0^{\star}$ & 26.1 \\
Q15 Tremor in the limbs & $12.2^{\star}$ & 7.8 \\
Q23 Dullness in the limbs & $37.7^{\star}$ & 31.1 \\
Q44 Increased sensitivity of the skin on the extremities & $13.9^{\star}$ & 8.4 \\
Q47 Reduced grasp power & $18.3^{\star}$ & 12.3 \\
Q34 Reduced sexual desire & $18.7^{\star}$ & 12.6 \\
Q50 Rough skin & $27.7^{\star \star}$ & 18.2 \\
\hline
\end{tabular}

${ }^{\star} \mathrm{p}<0.05,{ }^{\star \star} \mathrm{p}<0.01$ by $\chi^{2}$ test or Fisher's exact method.

sensory conduction velocities of the spinning or refining workers were significantly lower than those of the reference workers.

Psychological and neurobehavioural tests

A small but significant increase in the self rated depression scale scores was found in the workers exposed to $\mathrm{CS}_{2}$ (table 1), and a regression coefficient of the exposed workers in the multiple regression model remained significant $(1.3 ; 95 \%$ CI 0.2 to 2.5$)$. The self rated depression scale score of the other exposed workers was the highest (38.8 (9.3)) among the three job categories, and it was increased significantly compared with that of the reference group. Among the neurobehavioural test items we examined, digit span (backward) was significantly lower in the exposed workers, although the difference was marginal (table 1).

\section{Subjective symptoms}

Of 54 subjective symptoms, those complained of more often by the workers exposed to $\mathrm{CS}_{2}$ were heavy feeling in the head, light headedness, fainting after suddenly standing up, tremor in the extremities, dullness in the extremities, increased sensitivity of the skin on the extremities, reduced grasping power, reduced sexual desire, and rough skin (table 3). Odds ratios (ORs) for these symptoms, except for tremor in the extremities, stayed significant after simultaneous adjustment for potential confounders with a multiple logistic regression analysis (data not shown).

The figure illustrates the prevalence of these symptoms by three exposure categories (spinning or refining workers $v$ other exposed workers $v$ reference workers). After controlling for possible confounders, ORs of the spinning or refining workers were significantly higher than ORs of the reference workers for four symptoms, which were dullness in the extremites, increased sensitivity of the skin on the extremities, reduced grasping power, and rough skin (ORs 1.45, 2.12, 1.88, and 2.05, respectively), whereas those of the other exposed workers were $>1.0$ but not significant (ORs 1.39, 1.43, 1.55, and 1.23, respectively). Deviance and Pearson $\chi^{2}$ statistics indicated goodness of fit of the models constructed (data not shown).

EFFECTS ON THE ENDOCRINE SYSTEM AND OTHER BIOCHEMICAL INDICES

Table 4 shows the effect of exposure to $\mathrm{CS}_{2}$ on the endocrine system and other organs, including the liver. Serum insulin concentration was lower in the exposed workers, whereas blood glucose concentration was unchanged. Glycosylated haemoglobin concentration, which is less affected by dietary intake, was also slightly increased in the workers exposed to $\mathrm{CS}_{2}$. These changes remained significant after controlling for possible confounders. The difference from the reference group, however, was larger in the other exposed workers than in the spinning or
Q1 Heavy feeling in the head

Q10 Light headedness

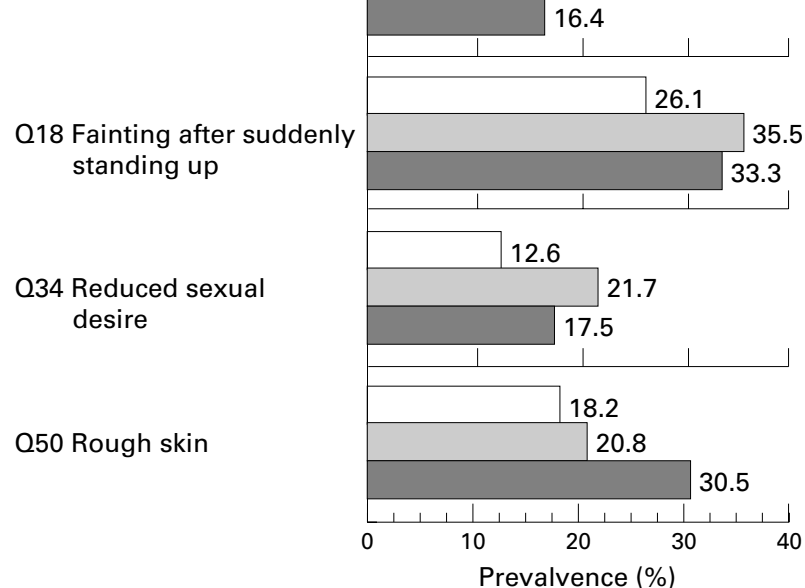

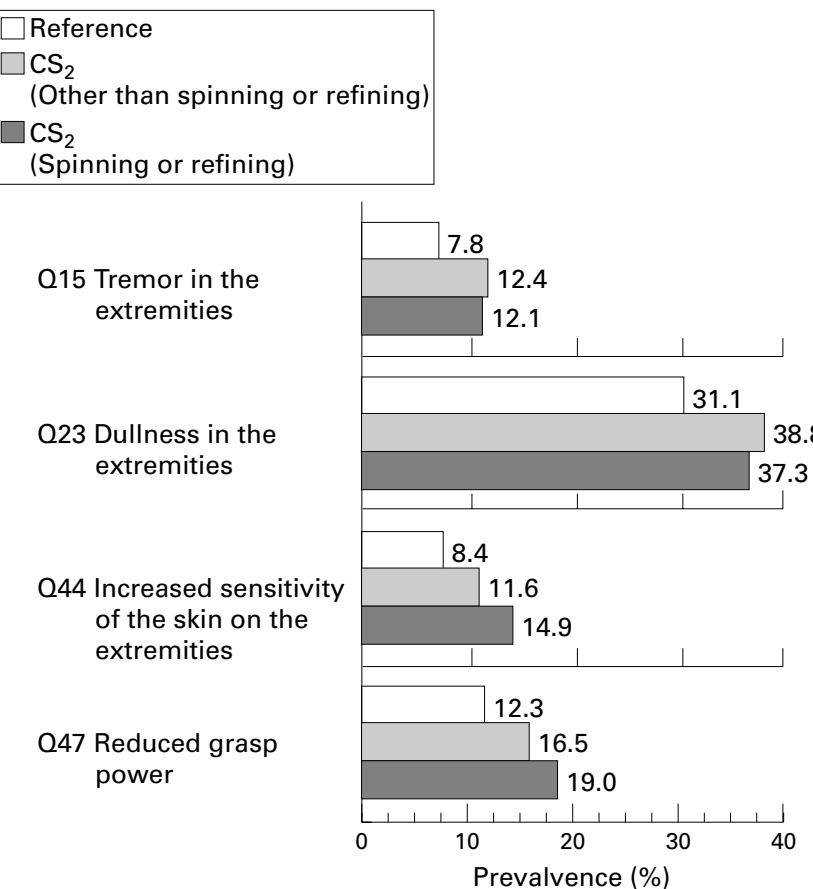

Prevalvence (\%)

Prevalence (\%) of subjective symptoms related to exposure to $\mathrm{CS}_{2}$ by job. Number of the spinning or refining workers, other exposed workers, and reference workers analysed were 298,121 , and 383, respectively. 
Table 4 Effects of exposure to $\mathrm{CS}_{2}$ on the endocrine system and other biochemical indices

\begin{tabular}{lcc}
\hline Variable & Exposed to $C S_{2}(n=428)$ & Reference $(n=396)$ \\
\hline Glucose metabolism: & & \\
Blood glucose $(\mathrm{mg} / \mathrm{dl}) \dagger$ & $99.9(1.2)$ & $101.5(1.2)$ \\
Insulin $(\mu \mathrm{U} / \mathrm{ml}) \dagger$ & $7.25(2.51)^{\star \star}$ & $9.02(2.43)$ \\
Glycocylated haemoglobin $(\%)$ & $5.12(0.48)^{\star}$ & $5.06(0.45)$ \\
Hypothalamo-hypophysial axis: & $5.58(1.71)$ & $5.39(1.76)$ \\
FSH $(\mathrm{mIU} / \mathrm{ml}) \dagger$ & $3.90(1.67)$ & $3.82(1.71)$ \\
LH $(\mathrm{mIU} / \mathrm{ml}) \dagger$ & $32.4(1.7)$ & $31.5(1.6)$ \\
ACTH $(\mathrm{pg} / \mathrm{ml}) \dagger$ & & \\
Gonad: & $488.7(163.5)$ & $469.0(149.5)$ \\
Testosterone $(\mathrm{ng} / \mathrm{dl})$ & & \\
Thyroid: & $0.91(9.06)$ & $0.85(10.45)$ \\
TSH $(\mu \mathrm{U} / \mathrm{ml}) \dagger$ & $1.18(1.17)$ & $1.15(1.14)$ \\
T3 $(\mathrm{ng} / \mathrm{ml}) \dagger$ & $8.59(1.74)$ & $8.69(1.56)$ \\
T4 $(\mu \mathrm{g} / \mathrm{dl})$ & $20.9(4.1)$ & $20.5(3.6)$ \\
TBG $(\mu \mathrm{g} / \mathrm{ml})$ & & \\
Other biochemical indices: & $22.2(1.4)$ & $22.6(1.4)$ \\
AST $(\mathrm{IU} / \mathrm{l}) \dagger$ & $19.7(1.8)$ & $20.2(1.7)$ \\
ALT $(\mathrm{IU} / \mathrm{l}) \dagger$ & $30.1(2.1)$ & $7.38(0.43)$ \\
$\gamma-\mathrm{GTP}(\mathrm{IU} / \mathrm{l}) \dagger$ & $7.35(0.40)$ & $169.3(1.3)$ \\
Total $\mathrm{protein}(\mathrm{g} / \mathrm{dl})$ & $173.5(1.3)$ & $307.0(1.2)$ \\
ALP $(\mathrm{IU} / \mathrm{l}) \dagger$ & $310.0(1.2)$ & $0.46(1.60)$ \\
LDH $(\mathrm{IU} / \mathrm{l}) \dagger$ & $0.44(1.73)$ & $5.48(1.20)$ \\
Total bilirubin $(\mathrm{mg} / \mathrm{dl}) \dagger$ & $5.52(1.28)$ & \\
Uric acid $(\mathrm{mg} / \mathrm{dl})$ & &
\end{tabular}

${ }^{\star} \mathrm{p}<0.05,{ }^{\star \star} \mathrm{p}<0.01$ by student's $t$ test or Welch's method.

†Indicates geometric mean (GSD).

Values are mean (SD) unless otherwise specified.

refining workers, even if the workers who had changed job were excluded from the analysis. Hormones of the hypothalamo-hypophysial axis, gonad, and thyroid, and the biochemical indices in blood did not show any changes related to exposure to $\mathrm{CS}_{2}$.

\section{Discussion}

Many authors have reported extensive $\mathrm{CS}_{2}$ toxicity on the peripheral nervous system. ${ }^{1{ }^{425-30}}$ In this cross sectional study, occupational exposure to $\mathrm{CS}_{2}$ in the spinning and refining processes caused significant reduction in the median nerve conduction velocities compared with those of the reference workers even after controlling for potential confounders such as age, obesity, and alcohol drinking. The findings were coincident with an increase in the prevalence of symptoms of the peripheral nervous system. We, however, found that indices of glucose metabolism in the exposed workers were slightly but significantly changed compared with those in the reference workers. As the disturbance of glucose metabolism causes disorders of the peripheral nerves, it is possible that an increase in concentration of glycosylated haemoglobin may confound the association between exposure to $\mathrm{CS}_{2}$ and reduction in the nerve conduction velocities. To examine this possibility, we ran the multiple regression models adding concentration of glycosylated haemoglobin as an explanatory variable, but this inclusion did not change the regression coefficients of exposure to $\mathrm{CS}_{2}$ variables much, which suggests that the association was not significantly confounded by concentration of glycosylated haemoglobin. Glycosylated haemoglobin was not collinear with exposure to $\mathrm{CS}_{2}$ when checked by collinearity tests. ${ }^{31}$

Magnitudes of the reduction were $1.94 \mathrm{~m} / \mathrm{s}$ (motor conduction velocity) or 0.91 and 1.15 $\mathrm{m} / \mathrm{s}$ (orthodromic and antidromic sensory conduction velocities) for the spinning or refining workers. Similar small but significant reductions of the peripheral nerve conduction veloc- ity at relatively low $\mathrm{CS}_{2}$ concentrations have been consistently reported. ${ }^{40}$ As the study subjects examined by industrial physicians were free from clinically diagnosed peripheral nerve disorders, it could be argued that the health significance of these changes in the nerve conduction velocities should be examined. In our multiple regression analysis, the effects of exposure to $\mathrm{CS}_{2}$ (spinning or refining) were larger than or similar to the effects of aging (10 years), which were $0.63 \mathrm{~m} / \mathrm{s}$ on motor conduction velocity, and 1.12 and $1.19 \mathrm{~m} / \mathrm{s}$ on sensory conduction velocities. We think that this impact is not negligible, and a follow up study is needed to examine the reversibility of these effects under the current work environment.

Effects of exposure to $\mathrm{CS}_{2}$ on the central nervous system have also been well established, and an increase in the prevalence of subjective symptoms was noted, including headache, memory impairment, rapid mood change, insomnia, paraesthesia, and fatigue at $\mathrm{CS}_{2}$ concentrations of 7-30 ppm. ${ }^{2}$ Similar results were obtained in this study; workers exposed to $\mathrm{CS}_{2}$ complained more often than unexposed workers of such symptoms as heavy feeling in the head or increased sensitivity of the skin on the extremities. Reduced sexual desire and symptoms relating to disturbance of sexual behaviour also occurred in the exposed workers, as has been noted previously as lessening of libido at higher concentrations of $\mathrm{CS}_{2}{ }^{32}$ or even at lower concentration. ${ }^{33}$ Among the neurobehavioural and psychological test items we examined, reduced cognitive function (verbal memory) and depressive mood were found in the workers exposed to $\mathrm{CS}_{2}$, whereas sensorimotor and perceptual-motor functions, visual memory function, and anxiety mood were unaltered. The detected differences with relation to exposure to $\mathrm{CS}_{2}$, however, were marginal, and their relavence to health is unclear.

Reinhardt et $a l^{34}$ conducted an epidemiological study in a German factory producing viscose, in which median urinary TTCA concentration was $1.43 \mathrm{mg} / \mathrm{g} \mathrm{Cr}$, and suggested that there were no associations between exposure to $\mathrm{CS}_{2}$ and various effects on the nervous system evaluated by a questionnaire about subjective symptoms, neurobehavioural tests, and a clinical examination. The discrepancy between that study and our results could be explained by differences between the two study populations in current average or peak concentrations of $\mathrm{CS}_{2}$, effect of past exposure, and individual susceptibility. However, it is also possible that a bias resulted from the exposed workers reporting their symptoms in a different manner than the reference workers because they knew that exposure to $\mathrm{CS}_{2}$ could impair their health. A careful follow up study with precise exposure assessment will be necessary so that an exposure-response relation between exposure to $\mathrm{CS}_{2}$ and prevalence of subjective symptoms can be found if the association is causal.

Interpretation of the result of exposure to $\mathrm{CS}_{2}$ on glucose metabolism must be made with 
caution because the difference was small and fasting was not required before blood sample collection. The noted increase in glycosylated haemoglobin, which is less affected by diet intake, may support the theory that exposure to $\mathrm{CS}_{2}$ could affect glucose metabolism. In studies with workers exposed to $\mathrm{CS}_{2}$, a positive prednisolone glucose tolerance test ${ }^{9}$ or increased blood glucose concentration and impaired glucose tolerance to oral cortisone ${ }^{10}$ were reported. Recently, to the contrary, it has been reported that there was no association between blood glucose concentration and exposure to $\mathrm{CS}_{2} \cdot{ }^{35}{ }^{36}$ Fasting blood samples and glucose tolerance tests will be necessary to evaluate whether low level exposure to $\mathrm{CS}_{2}$ impairs glucose metabolism. Other endocrinological indicators did not show any associations with exposure to $\mathrm{CS}_{2}$. This may indicate that the hypothalamo-hypophysial axis, gonad, and thyroid are less vulnerable to exposure to $\mathrm{CS}_{2}$ than are the peripheral nervous system or glucose metabolism. We cannot, however, exclude the possibilities that unevaluated factors might confound the effect of $\mathrm{CS}_{2}$, or that bias may have occurred if healthier workers tended to be engaged in exposed jobs. Relatively wide variations of the outcome variables between and within workers could be responsible for these non-significant results.

Due to the nature of a cross sectional study, there are several limitations to interpreting the results. Firstly, a temporal causal association ${ }^{37}$ cannot be confirmed or denied, although general health conditions of most of the workers were fair or better at the time of employment. More importantly, exposure concentration in the past is difficult to estimate retrospectively because approaches to industrial hygiene and the use of appropriate personal protective equipment have been continuously improving the working environment. Also, in the Japanese rayon factories $\mathrm{CS}_{2}$ concentration in the air of workplaces has been reduced and exposure of workers has decreased over time. As we could not obtain an objective industrial hygiene record in the 1970 s or 1980 s, it was hard to estimate past or long term exposures. We did not combine data on exposure to $\mathrm{CS}_{2}$ that we measured (urinary TTCA concentrations in 1992) with the outcome data in this paper because such exposure estimates may not be a good surrogate for an accurate measure of a long term exposure.

The possible inference that we could draw from our results is that high exposure to $\mathrm{CS}_{2}$ in the past might induce such subclinical health effects as reduction in the peripheral nerve conduction velocities or an increase in the prevalence of subjective symptoms, and that these are not being entirely ameliorated under the current exposure to $\mathrm{CS}_{2}$. The possibility that exposure to $\mathrm{CS}_{2}$ at present may cause the positive findings in this population should also be considered. A follow up of this cohort planned for 1998-9 is necessary to further explore these questions, and may provide useful information allowing us to elucidate the effect of exposure or exposure-response relations.

We are indebted to Drs K Takahashi, T Hamaguchi, A Fujino, $\mathrm{H}$ Yamato, and I Kabe at the University of Occupational and Environmental Health, and at Keio University for administering the neurobehavioural tests. This study was supported by the Japan Chemical Fiber Association.

\footnotetext{
1 Beauchamp RO Jr, Bus JS, Popp JA, et al. A critical review of the literature on carbon disulfide toxicity. Crit Rev Toxicol 1983;11:169-278.

2 World Health Organization. Carbon dislufide. Geneva: World Health Organization, 1979

3 Seppalainen AM, Tolonen M. Neurotoxicity of long-term exposure to carbon disulfide in the viscose rayon industry. A neurophysiological study. Work Environ Health 1974;11:
145-53.

4 Johnson BL, Boyd J, Burg JR, et al. Effects on the peripheral nervous system of workers' exposure to carbon disulfide. Neurotoxicology 1983;4:53-65.
}

\section{Appendix: Questionnaire for subjective symptoms related to solvents}

Have you experienced the following symptoms within the past 6 months? (Choose from No, Occasionally, or Always). Please indicate a cause (s) of the symptoms if any.

\begin{tabular}{|c|c|}
\hline 1 Heavy feeling in the head & 28 Loose bowels \\
\hline 2 Headache & 29 Bound bowels \\
\hline 3 Dizziness & 30 Body weight loss \\
\hline 4 Nausea & 31 Feverishness \\
\hline 5 Vomiting & 32 Changes in perspiration pattern \\
\hline 6 Difficulty in sleeping & 33 Irregular menstruation (women only) \\
\hline 7 Nightmare & 34 Reduced sexual desire \\
\hline 8 Anxiety & 35 Dimmed vision \\
\hline 9 Nervousness & 36 Strained eyes \\
\hline 10 Light headedness & 37 Ringing ears \\
\hline 11 Muddle headedness & 38 Loss in hearing capacity \\
\hline 12 Loss of consciousness & 39 Difficulty in speech \\
\hline 13 Forgetfulness & 40 Reduced sense of smell \\
\hline 14 Inability to concentrate & 41 Reduced sense of taste \\
\hline 15 Tremor in the extremities & 42 Unusual taste \\
\hline 16 Cramp in the extremities & 43 Joint pain \\
\hline 17 Convulsion & 44 Increased sensitivity of skin on the extremities \\
\hline 18 Fainting after the suddenly standing up & 45 Chill sensation in extremities \\
\hline 19 Palpitation & 46 Abnormal feeling of the skin on the extremities \\
\hline 20 Tightness in the chest & 47 Reduced grasping power \\
\hline 21 Breath shortage & 48 Reduced muscle power in the extremities \\
\hline 22 General dullness & 49 Prone to stumble during walking \\
\hline 23 Dullness in the extremities & 50 Rough skin \\
\hline 24 Poor appetite & 51 Unusual feeling in the throat \\
\hline 25 Abdominal pain & 52 Frequent cough \\
\hline 26 Dry mouth & 53 Frequent bleeding from gums \\
\hline 27 Stomach upset & 54 Reduced tolerance to alcohol \\
\hline
\end{tabular}

Original version of the questionnaire was derived from Inoue ${ }^{19}$ in Japanese, and this English translation was referred to as that of Uchida et al. ${ }^{20}$ 
5 Putz-Anderson V, Albright BE, Lee ST, et al. A behavioural examination of workers exposed to carbon disulfide. examination of workers exp
Neurotoxicology $1983 ; 4: 67-77$.

6 Aaserud O, Hommeren OJ, Tvedt B, et al. Carbon disulfide exposure and neurotoxic sequelae among viscose rayon workers. Am 7 Ind Med 1990;18:25-37.

7 Ruijten MW, Salle HJ, Verberk MM, et al. Special nerve functions and colour discrimination in workers with long term low level exposure to carbon disulphide. $\mathrm{Br} F$ Ind $\mathrm{Med}$ 1990;47:589-95.

8 Cassitto MG, Camerino D, Imbriani M, et al. Carbon disulfide and the central nervous system: a 15-year neurobehavioral surveillance of an exposed population. Environ Res 1993;63:252-63.

9 Goto S, Hotta R, Sugimoto K. Studies on chronic carbon disulfide poisoning. Pathogenesis of retinal microaneurysm due to carbon disulfide, with special reference to a subclinical defect of carbohydrate metabolism. Int Arch subclinical defect of carbohyd
Arbeitsmed 1971;28:115-26.

10 Candura F, Franco G, Malamani T, et al. Altered glucose tolerance in carbon disulfide exposed workers. Acta Diabetolerance in carbon disulfide
tol Latina 1979;16:259-63.

11 Cavalleri A, Djuric D, Maugeri U, et al. Endocrinological findings in young workers exposed to carbon disulphide. III. Urinary excretion of 3 $\alpha, 11$-deoxy-17-ketosteroids. Med Lav 1966;57:755-60.

12 Cavalleri A, Djuric D, Visconti E, et al. Endocrinological findings in young workers exposed to carbon disulphide. II Urinary excretion of 17-hydroxycorticosteroids. Med Lav 1966;57:573-8.

13 Cavalleri A, Djuric D, Maugeri U, et al. Endocrinological findings in young workers exposed to carbon disulphide. I. Urinary excretion of total 17-ketosteroids. Med Lav 1966; 57:566-72.

14 Cavalleri A. Serum thyroxine in the early diagnosis of carbon disulfide poisoning. Arch Environ Health 1975;30: 85-7.

15 Cirla AM, Bertazzi PA, Tomasini M, et al. Study of endocrinological functions and sexual behaviour in carbon disulphide workers. Med Lav 1978;69:118-29.

16 El-Sobkey MK, Massoud AA, Abdel-Karim AH, et al. Serum thyroxine, serum cholesterol and its fractions in workers exposed to carbon disulphide. F Egypt Public Health Assoc 1979;54:431-42.

17 Vanhoorne M, Vermeulen A, De Bacquer D. Epidemiological study of endocrinological effects of carbon disulfide. Arch Environ Health 1993;48:370-5.

18 Omae K, Takebayashi T, Nomiyama T, et al. Cross sectiona observation of the effects of carbon disulphide on arteriosclerosis in rayon manufacturing workers. Occup Environ Med 1998;55:468-72.

19 Inoue T. A table of subjective symptom questionnaires for solvent workers. In: Japan Industrial Safety and Health Association, ed. Health management of solvent workers. Tokyo: JISHA, 1983:66-7.
20 Uchida Y, Nakatsuka H, Ukai H, et al. Symptoms and signs in workers exposed to predominantly to xylenes. Int Arch Occup Environ Health 1993;64:597-605.

21 Taylor J. A personality scale of manifest anxiety. $\mathcal{F}$ Abnorm Soc Psychol 1953:285-90.

22 Zung W. A self-rating depression scale. Arch Gen Psychiatry 1973;12:63-77.

23 Henry, JB. Clinical diagnosis and management by laboratory methods. 19th ed. Philadelphia: WB Saunders, 1996.

24 Tietz NW. Clinical guide to laboratory test, 3rd ed. Philadelphia: WB Saunders Co, 1995.

25 Vasilescu C. Motor nerve conduction velocity and electromyogram in carbon disulphide poisoning. Revue Roumaine de Neurologie 1972;9:63-71.

26 Seppalainen AM, Hernberg S. Sensitive technique for detecting subclinical lead neuropathy. $\mathrm{Br} f$ Ind $\mathrm{Med}$ 1972;29:443-9.

27 Knave B, Kolmodin-Hedman B, Persson HE, et al. Chronic exposure to carbon disulfide: effects on occupationally exposed workers with special reference to the nervous system. Work Environ Health 1974;11:49-58.

28 Vasilescu C. Sensory and motor coduction in chronic carbon disulphide poisoning. Eur Neurol 1976;14:447-57.

29 Vasilescu C, Florescu A. Clinical and electrophysiological studies of carbon disulphide polyneuropathy. $\mathcal{F}$ Neurol 1980;224:59-70.

30 Ruijten MW, Salle HJ, Verberk MM. Verification of effects on the nervous system of low level occupational exposure to $\mathrm{CS}_{2}$. Br f Ind Med 1993;50:301-7.

31 Kleinbaum D, Kupper L, Muller K, eds. Applied regression analysis and other multivariate methods. 2nd ed. California: Duxbury, 1987.

32 Braceland F. Mental symptoms following carbon sulfide absorption and intoxication. Ann Intern Med 1942;16:24661.

33 Vanhoorne M, Comhaire F, De Bacquer D. Epidemiological study of the effects of carbon disulfide on male sexuality and reproduction. Arch Environ Health 1994;49:273-8.

34 Reinhardt F, Drexler H, Bickel A, et al. Neurotoxicity of long-term low level exposure to carbon disulphide-results of questionnaire, clinical neurological examination and neuropsychological testing. Int Arch Occup Environ Health 1997;69:332-38.

35 Egeland GM, Burkhart GA, Schnorr TM, et al. Effects of exposure to carbon disulphide on low density lipoprotein cholesterol concentration and diastolic blood pressure. $\mathrm{Br} \mathcal{F}$ Ind Med 1992;49:287-93.

36 Drexler H, Ulm K, Hubmann M, et al. Carbon disulphide. III. Risk factors for coronary heart diseases in workers in the viscose industry. Int Arch Occup Environ Health 1995;67:243-52.

37 Rothman K. Modern epidemiology. Boston: Little, Brown, 1986. 